\title{
O FAZER E PENSAR: COMO PENSA O LEGISLADOR - PRÁTICAS E IDEOLOGIAS
}

\section{ARTIGO ORIGINAL}

LEAL, Cícero Pereira ${ }^{1}$

LEAL, Cícero Pereira. O Fazer e Pensar: Como pensa o Legislador - práticas e ideologias. Revista Científica Multidisciplinar Núcleo do Conhecimento. Ano 05, Ed. 12, Vol. 18, pp. 116-130. Dezembro de 2020. ISSN: 2448-0959, Link de acesso: https://www.nucleodoconhecimento.com.br/ciencias-sociais/praticas-eideologias

\section{RESUMO}

O trabalho tem como objetivo identificar na literatura algumas características que compõe e influenciam as decisões das políticas públicas. Podemos inferir que as ideologias: pessoais, sociais e partidárias exercem influência nas votações dos representantes do Parlamento. Para tanto, realizamos um levantamento bibliográfico onde encontramos algumas características, que não exclui outras que possam ser contempladas em outros estudos. Dessa forma, foi observado que questões pessoais, sociais e políticas, podem gerar alteração no comportamento - direta ou indiretamente - dos representantes eleitos pela sociedade, conduzindo mudanças no processo de votação, ora atendendo agendas: pessoais, sociais e/ou partidária. $\mathrm{O}$ trabalho foi dividido em uma introdução da literatura seminal onde trata dos representantes préselecionados por todos, mas não respondendo a ninguém. Na segunda parte, apresentamos os caminhos percorridos para o desenvolvimento do trabalho. A literatura teórica é demostra na terceira parte e as considerações deixamos na quarta parte do texto.

1 Mestrado em Gestão Econômica do Meio Ambiente, Graduação em Ciências Econômicas. 
Palavras chaves: Ideologia, perfil parlamentar, polarização, permutas.

\section{INTRODUÇÃO}

O filósofo francês Jean-Jacques Rousseau, foi um dos primeiros pesadores da cultura política hegemônica. Ele pretendia desenvolver um modelo político que assegurasse a democracia, já que a propriedade privada promove a desigualdade e, coloca em perigo a liberdade. Um modelo político que estabelecesse um estado, amparasse a propriedade privada e determinasse a propriedade pública como algo de todos sem pertencer a nenhuma pessoa. Dessa forma, a representação política ficaria a serviço de todos, contudo, sendo de todos, não pertenceria a ninguém. Segundo Rousseau, a representação política partiria da "vontade de todos" da sociedade para a "vontade geral", ou seja, os representantes pré-selecionados por todos, mas não respondendo a ninguém. Segundo Carl Schmitt, representar significa tornar presente um ausente, ou seja, ninguém (BENJAMIN, 2008).

Os conceitos de Rousseau foram inseridos na Constituição dos Estados Unidos e nas constituições consequentes da Revolução Francesa. A Revolução Francesa gerou uma mudança histórica do sistema-mundo moderno, apresentando duas alterações fundamentais, que organizaram a base da cultura política do sistema-mundo moderno: a normalidade da mudança política e a reformulação do conceito de soberania, com o foco no povo-cidadão. O entendimento de soberania popular, se era inclusivo, resultou na exclusão de grande maioria das pessoas. Os séculos XIX e XX, apresentou um debate entre incluídos e excluídos, essa discussão aconteceu em uma geocultura que expressava a inclusão de todos como sinônimo de uma sociedade justa (PINTO; GUIMARÃES; BARROS, 2016).

Conforme Ceron (2015), os partidos atuam como atores, sendo dessa forma, os membros exibem o comportamento de acordo com a sua legenda. No entanto, essa afirmação não reflete a realidade. As partes não são estruturas de monopólio político, já que geralmente são compostos por uma variedade de subgrupos (ou seja, facções) mantendo semelhantes, mas não idênticas preferências. Cientes de tal heterogeneidade interna, os estudiosos têm investigado os elementos que impactam 
no nível da unidade partidária para avaliar as condições sob quais deputados pertencentes ao mesmo grupo se comportam de forma consistente ou (melhor) escolher opções diferentes.

Estudos sobre unidade partidária apresenta diversas respostas para este fenômeno (heterogeneidade). Além de alguns trabalhos comparativos avaliando o impacto de diferentes sistemas políticos (Carey, 2007, 2009; Depauw e Martin, 2009; Kam, 2009; Sieberer, 2006), citado por Ceron (2015), onde uma série de artigos analisam a unidade partidária em um único país. Esses trabalhos lançam luz sobre os elementos que afetam a disposição para divisões partidárias. Eles chamam a atenção para a heterogeneidade das preferências políticas, o grau de partidarismo, o impacto de regras eleitorais contrastantes ou modos de organização partidária, as diferenças entre governo e oposição, a margem da coalizão no poder e o tamanho do partido. No geral, os estudiosos identificaram dois caminhos principais para a unidade partidária: coesão (homogeneidade das preferências políticas) e disciplina (sanções previstas). Ambos os elementos são cruciais e são levados em consideração para explicar o comportamento eleitoral dos representantes (Bowler et al., 1999; Hazan, 2003) referenciado em (CERON, 2015).

Com relação à primeira via (coesão), a relação entre filiação partidária e preferências políticas divergentes foi investigada em trabalhos recentes. Em outro estudo de caso relativo à filiação partidária nos Democratas de Esquerda Italianos (DS), Giannetti e Laver (2009) citado por Ceron (2015), destacam como as preferências fracionais divergentes alteram o grau de unidade partidária e explicam a variação no comportamento eleitoral dos deputados. Ceron (2015), apresentando Spirling e Quinn (2010), demonstrando que as preferências faccionais podem ser vinculando dentro do partido apresentando uma polarização como comportamento eleitoral.

Por outro lado, Ceron (2015), destaque que, quando a disciplina não é efetiva, a heterogeneidade intrapartidária dá origem a um comportamento eleitoral heterogêneo, exercendo um declínio na agenda partidária. Pelo contrário, quando a liderança pode contar com recursos efetivos de disciplina, ela será capaz de impor, e o comportamento dos deputados apresentará homogeneidade e aderência com a 
agenda partidária. Dessa forma, a polarização não exerce mais efeitos significativos sobre unidade partidária

\section{CAMINHOS METODOLÓGICOS DA PESQUISA}

Para a efetivação desse trabalho foi realizada ampla pesquisa bibliográfica, a qual resultou em material de análise extremamente importante, considerando o tema abortado. A proposta é verificar na literatura o debate referente ao comportamento do eleitor parlamenta e apresentar as ideologias como função de influência do comportamento das ações dos representantes do legislativo. Contemplando no final do trabalho, as questões propostas quanto à definição e atributos que recobrem o perfil e as práticas dos membros do parlamento, assim como os mecanismos institucionais que possibilitaram a existência e a reprodução desse grupo.

\section{REFERENCIAL TEÓRICO}

Conforme Messenberg (2017), Norberto Bobbio é um dos principais defensores do entendimento do pensamento de esquerda e direita. Ele apresenta em seu artigo Direita e esquerda: razões e significados de uma distinção política (1995), propondo uma variedade de princípios que - segundo Bobbio - podem ser observados nas ideologias de esquerda e de direita. Esclarece que a direita e a esquerda são blocos políticos homogêneos e/ou coerentes, entendendo que a esquerda tem uma agenda orientada para a igualdade entre os homens e para a modificação da ordem social, ao passo que a direita considera a desigualdade como algo inerente à humanidade $\mathrm{e}$ mantendo a conservação do ordenamento societário. Observando esses princípios em países industrializados e que mantem ideias recorrentes.

Dessa forma, a esquerda, prima o igualitarismo do livre comércio, o racionalismo, o laicismo, a crítica das limitações ético-religiosas, a não existência de opiniões absolutas de bem e mal, a falta de apreço à oligarquia, a conservação do meio ambiente e as demandas dos trabalhadores, que devem sobrepor a necessidade de crescimento econômico, o antifascismo e a identidade com as classes inferiores da sociedade. 
Já a direita - segundo Bobbio (1994) citado por Messenberg (2017), trabalha com outros ideais que compreendem: o individualismo, a hegemonia da propriedade privada e da livre iniciativa, a intuição, a precedência do sagrado, o reconhecimento da ordem e da tradição, a nobreza e o heroísmo, a inflexibilidade à diferença étnica, cultural e sexual, o militarismo e a segurança nacional, o crescimento econômico em prejuízo a conservação ambiental e das demandas dos trabalhadores, o anticomunismo e a identidades com as classes superiores da sociedade (MESSENBERG, 2017).

Assim sendo, no campo político, as cosmovisões[2] da esquerda e da direita compõem e se estendem "campo metapolítico das relações sociais cotidianas e da luta cultural" (Pierucci, 1990, p. 11) citado por (MESSENBERG, 2017). Sendo, modelos de alusão a partir dos quais os indivíduos entendem e relaciona-se com o mundo, constituindo significância à sua vivência e esclarecendo a "ordem das coisas".

Conforme Messenberg (2017), atualmente os meios de comunicação de massa e as redes digitais estabelecer ambientes singulares para a constituição dos enquadramentos[3], organizando e selecionando posições políticas. Tais enquadramentos, são consequências de um processo de mão dupla entre os emissores e os receptores do conhecimento, envolvendo a repetição de padrões interpretativos e compreensivos de forma seletiva e manipuladora, envolvendo valores e símbolos do entendimento comum, que são retroalimentados e/ou reformados de forma eficaz.

Além dos meios de comunicação e as ideologias partidária, à dimensão sociocultural, econômico e ideológico do fazer e pensar a política, pode ser representado pelo o perfil dos parlamentares. Identificar os atores e suas práticas políticas, e compreender de que maneira diferentes matizes socioculturais intervêm no processo de edificação e consolidação de suas carreiras e identidades enquanto políticos (MESSENBERG, 2007).

Bajoit (2006, p. 235) esclarece que cada indivíduo, encontra-se continuamente em (re)constituição, assumindo compromissos identitários: "tem uma certa ideia daquilo 
que é e do que queria vir a ser e daquilo que acredita dever fazer para isso". Nesse sentido, devemos entrar em relações sociais, participando de trocas, permutas e de ligações sociais. Logo, cada sujeito constrói lógicas de ação com os outros, imbuído de obter a sua identidade pessoal. Este processo contribui na construção do ator social, estando ele compromissado nas lógicas de ação por ele estabelecida na relação com o(s) outro(s). Para que o indivíduo possa resolver seus conflitos de sua vida, no intuito de minimizá-las ou solucioná-las, "ele esforça-se em reduzir ou aumentar o valor que atribui a certos traços das suas identidades desejadas, atribuídas e comprometidas, a fim de melhor as conciliar" (BAJOIT, 2006, p. 235). Este processo denomina-se gestão relacional de si.

A gestão relacional de si é também o trabalho através do qual o indivíduo "concebe" as lógicas de ação. O compromisso é a tradução da identidade comprometida em lógicas de ação sobre os outros. Levando em consideração a "ideia" que ele tem daquilo que é e quer vir a ser, e das possibilidades que lhe abrem ou the fecham os laços que ele tem com os outros nos diferentes campos relacionais, o indivíduo reconstrói constantemente os seus "projetos" de vida (BAJOIT, 2006, p. 236).

Cada indivíduo, portanto, age perante os outros para a realização dos seus compromissos para consigo mesmo, por meio de três maneiras: "estar sempre com eles em relações de permuta; participa, por vezes, em formas de solidariedade coletiva; e pode comprometer-se, por vezes, em ações coletivas" (BAJOIT, 2006, p. 236).

Em referência às relações de permuta, na tabela a seguir há a sistematização das lógicas de permuta estabelecidas pelos atores sociais para o alcance de seus objetivos, finalidades, identidades, etc., a partir de dois critérios que permitem distinguir, definir e classificar as suas formas, conforme demonstrado no quadro abaixo: 
Quadro 01: Lógicas de Permuta.

\begin{tabular}{|c|c|c|c|c|c|}
\hline \multirow{9}{*}{ 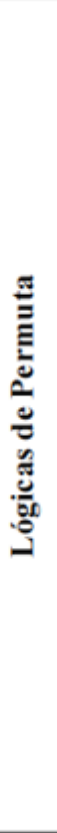 } & Critérios & Tipos & Permuta & Ação & Conceito \\
\hline & \multirow[t]{4}{*}{$\begin{array}{l}\text { Finalidades } \\
\text { da Permuta }\end{array}$} & \multirow[t]{2}{*}{ Inclusiva } & Complementar & Cooperar & $\begin{array}{l}\text { Cada ator só pode atingir sua finalidade } \\
\text { com a cooperação do outro. }\end{array}$ \\
\hline & & & Conflitual & Combater & $\begin{array}{l}\text { Deteriorização da cooperação. Cada parte } \\
\text { do conflito tem interesse em restabelecer } \\
\text { a cooperação. }\end{array}$ \\
\hline & & \multirow[t]{2}{*}{ Exclusiva } & Competitiva & Competir & $\begin{array}{l}\text { Um ator não pode atingir a sua finalidade } \\
\text { a não ser que impeça o outro de atingir a } \\
\text { sua. }\end{array}$ \\
\hline & & & Contraditória & Romper & $\begin{array}{l}\text { Cada ator tem interesse em suprimir o } \\
\text { outro, ou pelo menos, a relação com ele. }\end{array}$ \\
\hline & \multirow[t]{4}{*}{$\begin{array}{l}\text { A Estratégia } \\
\text { Relacional }\end{array}$} & \multirow[t]{2}{*}{ Consensuais } & Complementar & Cooperar & $\begin{array}{l}\text { Cada ator cumpre o seu papel para atingir } \\
\text { os objetivos coletivos e pessoais. }\end{array}$ \\
\hline & & & Competitiva & Competir & $\begin{array}{l}\text { Cada ator procura melhorar sua atuação } \\
\text { para estar à frente do outro, sem infringir } \\
\text { as regras. }\end{array}$ \\
\hline & & \multirow[t]{2}{*}{ Dimensionais } & Conflitual & Tumultuar & $\begin{array}{l}\text { Os atores deixam de estar de acordo e } \\
\text { põem em questão as condições da } \\
\text { cooperação. }\end{array}$ \\
\hline & & & Contraditória & $\begin{array}{l}\text { Destruir, } \\
\text { fugir }\end{array}$ & $\begin{array}{l}\text { Os atores não respeitam mais a relação, } \\
\text { destruindo ou fugindo dela. }\end{array}$ \\
\hline
\end{tabular}

Fonte: Bajoit (2006)

Considerando o quadro acima, infere-se que os atores sociais organizam diferentes lógicas de permuta para realizar suas identidades pessoais, com finalidades e estratégias diferentes. Assim sendo, cada critério produz tipos de lógicas de permuta que promoverá o fortalecimento ou não da relação entre os atores.

Corroborando para com a interpretação do quadro, Bajoit (2006, p. 241) sintetiza:

Podemos verificar também que cada uma dessas quatro lógicas se pode revestir de uma forma amplificada e de uma forma latente. A cooperação pode ser ativa ou passiva, o conflito pode ser aberto ou dissimulado, a contradição pode ser um confronto direto ou uma fuga, e a competição pode ser ofensiva ou reduzir-se a um simples oportunismo. Quanto mais as lógicas estão latentes, melhor se combinam entre si e coexistem; quanto mais elas estão amplificadas, mais se excluem reciprocamente.

Outra forma de os indivíduos relacionarem-se e realizarem seus compromissos para com os outros é por base das lógicas de solidariedade. Conforme Bajoit (2006, p. 242), "os indivíduos que escolhem a(s) lógica(s) de permuta têm muitas vezes (mas nem sempre) tendência a reconhecerem-se reciprocamente na ação, e a construir laços de 
solidariedade entre si". O reconhecimento para com a construção das relações entre os indivíduos, muitas vezes, passa pela questão do compromisso, pois para que possam realizar seus compromissos identitários, eles precisam um dos outros e, assim, se solidarizam.

As lógicas de solidariedade se dividem em duas, onde uma se baseia pela reciprocidade e a outra sobre a gregariedade, conforme o quadro abaixo:

Quadro 02: Lógicas de Solidariedade.

\begin{tabular}{|l|l|l|}
\hline Lógicas de solidariedade & Lógica de reciprocidade & Lógica de gregariedade \\
\hline Lógica expressiva & Solidariedade afetiva & Solidariedade fusional \\
\hline Lógica instrumental & Solidariedade contratual & Solidariedade serial \\
\hline
\end{tabular}

Fonte: Bajoit (2006)

O autor (idem) desenvolve sua teoria argumentando que, na lógica de reciprocidade, a solidariedade é uma relação baseada no "dom - contra dom", pois sempre há "alguma coisa" que é útil para alguém e que este alguém está disposto a trocar por outra coisa, ou por mais da mesma coisa de que necessita. A solidariedade se funde, se constrói e desconstrói, conforme o compromisso assumido e a necessidade de manter a relação. As "coisas" podem ter fundamentos diferenciados, sendo umas estabelecidas no afeto, na troca de uma ajuda moral ou afetiva, entendida como expressiva (conselhos, apoio, amor, carinho, respeito, etc.) e outras baseadas em aspectos materiais ou instrumentais (recursos materiais, competências, trabalho, informações, dinheiro, etc.).

$\mathrm{Na}$ solidariedade afetiva, a troca é muito mais subjetiva, e os indivíduos efetuam suas relações de compromisso de forma expressiva; dão afeto e o recebem em troca, para a realização da sua identidade pessoal. Quando as trocas são materiais ou instrumentais, os indivíduos realizam a solidariedade contratual, que obedece a uma relação objetiva e muito menos subjetiva. 
Segundo Bajoit (2006), na lógica da agregariedade, as relações de troca e realização de compromissos ligam-se mais às dinâmicas de grupos, sendo que, em grupo, os indivíduos podem dispor de alguma coisa que falta a todos separadamente, mas que quando então em conjunto, eles a possuem.

Neste entendimento, as coisas podem ser também divididas em dois aspectos: uma voltada a coisas de caráter e qualidade subjetivas (religião, causa, movimento social, luta, coragem de empreender, etc.) e aquelas cujas coisas são objetivas (força, segurança, anonimato, etc.). Quando as coisas que estão em troca, em relação, são de qualidade subjetiva, temos a lógica expressiva, cujo interesse está na necessidade de desenvolvê-las por meio de grupos, fundindo a identidade pessoal com a dos outros, que, juntos, fornecem qualidades que não haveriam se estivessem sozinhos, gerando a denominada solidariedade fusional. Em contrapartida, quando uma identidade pessoal passa a ter força e segurança somando-se com as de outros, criando um grupo forte, denomina-se de solidariedade serial. Em suma, estas quatro lógicas de solidariedade expressam a necessidade de articulação com os outros na realização de suas identidades pessoais, os quais, sozinhos, não teriam condições de se efetivarem.

Bajoit (2006, p. 243-244) reforça que os grupos sociais (família, igreja, grupos de trabalho, sindicatos, etc.) "são tanto mais sólidos quanto mais conseguem articular todas as lógicas: os seus membros estão, então, ligados entre si por todos os laços ao mesmo tempo". É válido ressaltar que as lógicas de solidariedade partem do foco na realização dos compromissos e das identidades pessoais individuais, sendo independentes das identidades coletivas. No entanto, Bajoit (2006, p. 244) destaca que:

Evidentemente, uma das condições indispensáveis à formação da solidariedade é a socialização dos indivíduos: que eles ocupem a mesma posição na relação, que participem na mesma identidade coletiva. No entanto, não é uma condição necessária: uma solidariedade pode formar-se entre indivíduos que não ocupam as mesmas posições sociais (é o caso dos altruístas, por exemplo), tal como pode também não se formar entre indivíduos que ocupam a mesma posição social (se adotam lógicas do sujeito e de permuta diferentes). Portanto, a solidariedade é 
não só qualquer coisa mais que a identidade, mas também qualquer coisa diferente. De uma forma mais geral, depende de um conjunto complexo de condições.

De acordo com a citação acima, o conjunto complexo de condições necessárias para que a solidariedade ocorra é o que Bajoit chama de ação coletiva, formada por condições que estimulam a mobilização social dos indivíduos envolvidos e de outros que adentrem à ação coletiva.

Tais condições classificam-se em três componentes da ação coletiva: a formação de uma solidariedade organizada; a composição de um adversário ou inimigo; e a elucidação dos objetivos da ação. Segundo Bajoit (2006, p. 248), a presença de indivíduos empenhados em algum desses componentes não é o suficiente para que a ação coletiva seja fecundada. Isto, sim, permite o estabelecimento da solidariedade, no entanto, a mobilização social durável, objetivando o alcance dos resultados desejados dependerá diretamente de uma organização constituída por dirigentes, recursos e tradições:

- Uma liderança de qualidade: unida, consistente, perseverante, independente, competente, visível, combativa, organizada, carismática;

- Recursos para a mobilização: dinheiro, relações, informações, armas (reais ou simbólicas);

- Tradições de lutas inscritas numa história comum, com sucessos e fracassos aos quais o grupo se possa referir para guiar a sua luta atualmente.

Percebe-se que a liderança é um fator de extrema importância para a efetividade da ação coletiva, seja ela qual for, seu objetivo ou finalidade. Nesse sentido, compreender as lideranças em empreendimentos econômicos solidários é significativo para o entendimento de quais lógicas de solidariedade e de permutas os indivíduos estabelecem nos grupos autogestionários, bem como se há lideranças que mobilizem a ação coletiva desses grupos em prol dos objetivos que eles estabelecem como estruturantes das suas identidades pessoais. 
O ator coletivo, ao se mobilizar, transforma as condições de sua existência, participando da (re)construção das suas próprias condições. Portanto, a mobilização social tem uma dinâmica própria, desencadeando certos processos:

Quadro 03: Processos de Mobilização Social

\begin{tabular}{|l|l|}
\hline Processo de Explicitação & $\begin{array}{l}\text { A mobilização obriga geralmente os atores a explicitar, clarificar, a tornar } \\
\text { visiveis os componentes da sua ação e a interpelar outros atores da cena } \\
\text { social, elaborando a sua ideologia, legitimando e aumentando os laços de } \\
\text { solidariedade interna no grupo. }\end{array}$ \\
\hline Processo de Complexificação & $\begin{array}{l}\text { Os objetivos, frequentemente, são simples no início, mas o movimento fará } \\
\text { surgir outros, desencadeando conflitos e aumentando a complexidade do } \\
\text { processo. }\end{array}$ \\
\hline Processo de Escalada & $\begin{array}{l}\text { Uma vez que os atores entram nas permutas, são frequentemente incitados a } \\
\text { nelas permanecerem, e até a comprometerem-se nelas cada vez mais. }\end{array}$ \\
\hline Processo de Avaliação & $\begin{array}{l}\text { Ao conhecerem-se melhor, os atores aprendem a prever as condutas do outro, } \\
\text { a organizar-se e a estabilizar a sua liderança, favorecendo a comunicação e, } \\
\text { por conseguinte, aprendem a respeitar-se, a compreender-se e a preparar a } \\
\text { institucionalização do conflito. }\end{array}$ \\
\hline
\end{tabular}

Fonte: Bajoit (2006, p. 250-251)

Explicando a tabela acima, percebe-se que os atores sociais iniciam suas lógicas de permuta, solidariedade e até de ação coletiva com base em processos que vão, desde o início, passando para processos mais profundos gerados pelos conflitos que surgem com o engajamento dos atores, sendo que $o$ ator explica o porquê de estabelecer a relação com o grupo. Com isto, a sua relação com a ação coletiva torna-se mais forte e o nível de comprometimento e responsabilidade que os demais membros exigem desse ator é cada vez maior, resultando processos de avaliação das ações realizadas no âmbito do grupo, analisando sua performance.

Segundo Messenberg (2007), essas características do Parlamento não são um fenômeno natural e são resultados do Poder Legislativo de tomar e impor decisões para os membros da instituição. A indicação de alguns parlamentares para a ocupação de cargos privilegiados e estratégicos na estrutura da organização, representando assim, uma elite parlamentar. Essa elite parlamentar é caracterizada na ocupação de postos-chave do Poder Legislativo, nos interesses sociais e/ou institucionais organizados e o reconhecimento dos pares de uma liderança, como característica individual. Assim sendo, são esses parlamentares que exercem 
influência nas principais decisões no Legislativo, Executivo e na sociedade. E suas influências podem conter dimensões culturais: interesses econômicos e sociais de indivíduos e grupos; identidades nacionais, sexuais, sociais, religiosas e partidárias. Portanto, Messenberg (2008), destaca que a cultura política, relaciona-se com processo de democratização, influenciando os atores nas decisões do Poder Legislativo.

Os relacionamentos geram identidades coletivas das quais as pessoas envolvidas edificam as suas identidades pessoais e se empenham em lógicas de ação com, sobre, contra, entre os outros; e por meio das quais eles reproduzem ou alternam os sentidos culturais (BAJOIT, 2006). Em contrapartida, Cavalcante (2012), entende que as diferenças políticas, culturais e institucionais não explicam ou explicam em partes, as variações das políticas públicas não negando a influência de fatores socioeconômicos na dinâmica política e os resultados das políticas pública. Compreende que as agendas de educação, saúde e assistência social são menos passíveis aos efeitos da política, à medida que habitação e saneamento tendem a sofrer com a influência desses fatores.

Bernabel (2015), trabalha as influências que podem desencadear a uma polarização política. O conceito de polarização e compreendido quando os membros de um determinado partido votam de uma maneira e os de outro partido votam de maneira diferente, esses dois partidos podem ser descritos como polarizados. Podendo existir várias causas para explicar a polarização. Bernabel (2015) cintando os autores McCarty, Poole e Rosenthal (2006), onde os mesmos argumentam que a renda, a imigração e o financiamento de campanhas podem gerar a polarização. Acrescenta também que, a forma (voto proporcional ou majoritário) como um legislador é eleito também pode ter um efeito na polarização. Os parlamentares eleitos pela regra majoritária, tendem a um comportamento mais extremado do que os eleitos pela regra proporcional, que votam mais com o seu partido. Paiva (2016), apresenta a análise de políticas públicas como um processo que envolve negociações, conflitos e disputas da agenda de políticas públicas, não descartando o poder de influenciar nas decisões do poder legislativo. 
Bajoit (2006), entende que a convivência em coletividade, em sociedade, em grupos, implica a solução de algumas questões importantes, dificuldades que se não solucionadas, pode colocar em perigo a existência individual. Dessa forma, podemos entender que os parlamentares procuram resolver conflitos objetivando a sua sobrevivência nos debates ideológicos, pessoais ou partidários.

\section{CONSIDERAÇÕES}

O filósofo francês Jean-Jacques Rousseau, foi um dos primeiros pesadores da cultura política hegemônica. Ele pretendia desenvolver um modelo político que assegurasse a democracia, já que a propriedade privada promove a desigualdade e, coloca em perigo a liberdade. Um modelo político que estabelecesse um estado, amparasse a propriedade privada e determinasse a propriedade pública como algo de todos sem pertencer a nenhuma pessoa. Dessa forma, a representação política ficaria a serviço de todos, contudo, sendo de todos, não pertenceria a ninguém.

Os partidos atuam como atores, sendo dessa forma, os membros exibem o comportamento conforme a sua legenda. No entanto, essa afirmação não reflete a realidade. As partes não são estruturas de monopólio político, já que geralmente são compostos por uma variedade de subgrupos (ou seja, facções) mantendo semelhantes, mas não idênticas preferências.

Norberto Bobbio é um dos principais defensores do entendimento do pensamento de esquerda e direita.

Eles chamam a atenção para a heterogeneidade das preferências políticas, o grau de partidarismo, o impacto de regras eleitorais contrastantes ou modos de organização partidária, as diferenças entre governo e oposição, a margem da coalizão no poder e o tamanho do partido. No geral, os estudiosos identificaram dois caminhos principais para a unidade partidária: coesão (homogeneidade das preferências políticas) e disciplina (sanções previstas). 
Além dos meios de comunicação e as ideologias partidária, à dimensão sociocultural, econômico e ideológico do fazer e pensar a política, pode ser representado pelo o perfil dos parlamentares.

Os indivíduos, encontra-se continuamente em (re)constituição, assumindo compromissos identitários: "tem uma certa ideia daquilo que é e do que queria vir a ser e daquilo que acredita dever fazer para isso". Nesse sentido, devemos entrar em relações sociais, participando de trocas, permutas e de ligações sociais.

As influências que podem desencadear a uma polarização política. O conceito de polarização e compreendido quando os membros de um determinado partido votam de uma maneira e os de outro partido votam de maneira diferente, esses dois partidos podem ser descritos como polarizados.

Entendemos, que esse estudo não contempla todas as diversidades, que produzem, divergências nas decisões dos votos dos parlamentares, necessitando, para um outro momento, amostras empíricas, das relações e comportamento dos indicados pela a sociedade. Assim sendo, existe uma lacuna para outros estudos ou trabalhos que averigue com dados e demonstre quantitativamente as verdadeiras preferências ou ideologias.

\section{BIBLIOGRAFIA}

ALDÉ, Alessandra. A construção da política: democracia, cidadania e meios de comunicação de massa. Rio de Janeiro: Editora FGV, 2004.

BAJOIT, Guy. Tudo muda: proposta teórica e análise de mudança sociocultural nas sociedades ocidentais contemporâneas. ljuí: Ed. ljuí, 2006.

BERNABEL, Rodolpho. A regra eleitoral é importante para a polarização política?

O Caso das Câmaras Legislativas Brasileiras. Bras. Political Sci. Rev. vol.9 no.2 São Paulo mai / ago. 2015. https://doi.org/10.1590/1981-38212014000200012. 
BENJAMIN, Cássio Corrêa. Schmitt e o problema da democracia. Nostalgia da transcendência ou a representação como questão para a democracia. Kriterion vol.49 no.118 Belo Horizonte Dec. 2008. https://doi.org/10.1590/S0100$512 \times 2008000200008$

BOBBIO, Norberto. Direita e esquerda: razões e significados de uma distinção política. São Paulo: Editora Unesp, 1994.

CAVALCANTE, P.L. C. A Política faz a diferença? Uma análise comparada dos determinantes políticos do desempenho dos governos municipais no Brasil. Tese apresentada como requisito parcial para a obtenção do Título de Doutor em Ciência Política pelo Programa de Pós-Graduação em Ciência Política da Universidade de Brasília. 2012.

CAVALCANTE, Pedro. A Implementação Municipal das Políticas Sociais: Uma Análise Espacial. Planejamento e políticas públicas | ppp | n. 42 | jan./jun. 2014.

CERON, Andrea. Brave rebels stay home: Assessing the effect of intra-party ideological heterogeneity and party whip on roll-call votes. Party Politics 2015, Vol. 21(2) 246-258, The Author(s) 2013 Reprints and permission: DOI: $10.1177 / 1354068812472581$

ENTMAN, Robert M. Democracy without citizens: media and the decay or american politics. New York: Oxford University Press, 1989

GOFFMAN, Erving. Os quadros da experiência social: uma perspectiva de análise. Petrópolis: Vozes. 2012.

MCCARTY, Nolan; POOLE, Keith and ROSENTHAL, Howard. Polarized America: The Dance of Ideology and Unequal Riches. MIT Press, Cambridge, MA. 240p. 2006.

MESSENBERG, Débora. A Elite Parlamentar Brasileira: Um Recorte Sociocultural. Rev. Sociol. Polít., Curitiba, v. 16, n. 30, p. 17-28, jun. 2008. 
MESSENBERG, Débora. A elite parlamentar brasileira (1989-2004). Sociedade e Estado, Brasília, v. 22, n. 2, p. 309-370, maio/ago. 2007.

MESSENBERG, Débora. O "alto" e o "baixo clero" do Parlamento brasileiro. Cadernos Aslegis, Brasília, v. 40, p. 79-107, mai./ago. 2010.

MESSENBERG, Débora. A direita que saiu do armário: a cosmovisão dos formadores de opinião dos manifestantes de direita brasileiros. Revista Sociedade e Estado - Volume 32, Número 3, Setembro/Dezembro 2017.

PAIVA, Ariane Rego de. Análise e avaliação de políticas sociais: algumas perspectivas do debate atual. O Social em Questão - Ano XIX - ํㅜ 36 - 2016

PIERUCCI, Antônio Flávio. Ciladas da diferença. Tempo Social, v. 2, n. 2, p. 7-37, 1990

PINTO, J. R. S; GUIMARÃES, D. M.; BARROS, F. L. A Crise da Democracia Representativa. E-legis, Brasília, n. 19, p. 39-48, jan./abr. 2016, ISSN 2175.0688

WEBER, Max. A objetividade do conhecimento na ciência social e na ciência política. Metodologia das ciências sociais, v. 1. São Paulo: Editora Unicamp, 1992.

\section{APÊNDICE - REFERÊNCIAS DE NOTA DE RODAPÉ}

2. A noção de cosmovisão (Weltanschauung) aqui adotada fundamenta-se no sentido weberiano (1992), o qual a relaciona aos valores ou princípios culturais que embasam as concepções do universo e das filosofias de vida de uma sociedade ou grupo. Além disso, como aponta Weber: "[...] cosmovisões nunca podem ser o resultado de um avanço do conhecimento empírico, e que, portanto, os ideais supremos que nos movem com a máxima forçam possível, existem, em todas as épocas, na forma de uma luta com outros ideais que são, para outras pessoas, tão sagrados como o são para nós outros" (Weber, 1992: 113). 
3. A noção de enquadramento é aqui tomada no sentido goffmaniano (Goffman, 2012) ou seja, como "estruturas cognitivas, que organizam o pensamento, são compostas de crenças, atitudes, valores e preferências, bem como de regras a respeito de como ligar diferentes ideias. São esquemas que 'dirigem atenção para a informação relevante, guiam sua interpretação e avaliação, fornecem inferências quando a informação é falha ou ambígua, e facilitam sua retenção"' (Fiske \& Kinder, citados por Entman, 1989, apud Aldé, 2004: 47).

Enviado: Novembro, 2020.

Aprovado: Dezembro, 2020. 